\title{
A Simple Model for Studying the Correction of In Utero Hypothyroidism in the Rat
}

\author{
JOSEPH SACK, ARON WELLER, OREN RIGLER, AND AVIRAM ROZIN \\ Department of Pediatrics [J.S.], Sheba Medical Center, Tel Hashomer and Sackler School of Medicine, \\ Tel Aviv University, and Department of Psychology [A.W., O.R., A.R.], Developmental Psychobiology \\ Laboratory, Bar Ilan University, Ramat Gan, Israel
}

ABSTRACT

\begin{abstract}
Although the placenta is only a limited barrier for the transfer of thyroxine $\left(\mathrm{T}_{4}\right)$ to the fetus, we have recently demonstrated that maternal $T_{4}$ does not suffice to prevent the effects of in utero hypothyroidism. The current study presents a convenient and minimally invasive animal model to study whether maternal-fetal transfer of $\mathrm{T}_{4}$ administered to the pregnant rat corrects the newborn's in utero hypothyroidism. In this model pregnant rats receive the goitrogen methimazole in their drinking water from $d$ 10 of gestation until birth, either alone or together with $\mathrm{L}^{-\mathrm{T}_{4}}$. Circulating $\mathrm{T}_{4}$ levels in the dams and newborn pups are measured from blood spotted on filter paper by RIA. Using blood $\mathrm{T}_{4}$ levels as the measure, in the present study we found similar
\end{abstract}

The issue of placental transport of thyroid hormones has been debated for ycars. It was previously thought that there was minimal placental transport of these hormones in humans and in rats. This was attributed either to poor permeability of the fetal membranes and/or to active deiodinating mechanisms (1-4). Recent data, however, have shown that the rat placenta actively metabolizes $T_{4}$ to $T_{3}$ and that thyroid hormones do cross the placenta in both humans and rats, so that the placenta acts only as a limited barrier (5-8).

We have shown that maternal-fetal transport of $\mathrm{T}_{4}$ in humans does not suffice to prevent in utero hypothyroidism (9). This conclusion is based on the observation that neonates with athyreotic congenital hypothyroidism are often born with more severe signs of hypothyroidism in the absence of epiphysial ossification centers and with extremely high TSH levels at birth. It has been claimed that maternal transfer of $\mathrm{T}_{4}$ could still provide the fetal brain with sufficient $\mathrm{T}_{3}$ to avoid major irreversible CNS damage if the fetal thyroid is not functional (5). These authors suggested that the fetal brain might be protected by maternal $\mathrm{T}_{4}$, even if the transfer is not sufficient to protect other tissues, and that delayed skeletal maturation does not necessarily imply that the brain was $\mathrm{T}_{3}$ deficient in utero.

Received June 10, 1994; accepted September 10, 1994.

Correspondence: Dr. Joseph Sack, Department of Pediatrics, Sheba Medical Center, Tel Hashomer, Israel.

A portion of this research was performed by Oren Rigler as partial fulfillment of the requirements for an M.A. degree in the Department of Psychology, Bar Ilan University. effects for orally and intraperitoneally administered $\Upsilon_{4}$. This rat model will allow future studies of whether maternal-fetal $T_{4}$ transfer can correct the detrimental neurobehavioral effects of intrauterine hypothyroidism. (Pediatr Res 37: 497-501, 1995)

$\mathbf{T}_{\mathbf{4}}$, thyroxine
$\mathbf{T}_{3}, 3,5,3^{\prime}$-triiodothyronine
$\mathbf{M M I}$, methimazole
$\mathbf{C V}$, coefficient of variance
i.p., intraperitoneal

However, the very high TSH levels evident already at birth suggest that the fetal pituitary lacks $\mathrm{T}_{3}$ for negative feedback. Several studies have shown that congenitally hypothyroid newborns with the most retarded bone maturation and with the lowest $\mathrm{T}_{4}$ levels at screening have the poorest prognosis for CNS development, despite prompt postnatal treatment with $\mathrm{T}_{4}$ $(10-13)$. These results imply that maternal $\mathrm{T}_{4}$ transfer fails to provide adequate prevention of in utero CNS developmental delay.

Although several studies support the existence of maternalfetal $\mathrm{T}_{4}$ transfer in rats, $\mathrm{T}_{4}$ was administered in these studies invasively, either intraperitoneally or through s.c. osmotic pumps. This could potentially produce a considerable degree of prenatal stress. Furthermore, none of these studies has followed the fetuses to birth. It would be of great value to have a rat model of in utero hypothyroidism in which the $\mathrm{T}_{4}$ treatment is administered orally without traumatic manipulation of the pregnant dam and the postnatal development of the pups could be assessed. We have previously reported on the efficacy of using blood spotted on filter paper for $\mathrm{T}_{4}$ measurement in the follow-up of children with congenital hypothyroidism (14). In the present study we applied this method, which requires only a drop of blood, to measure $\mathrm{T}_{4}$ in pregnant, postpartum, and newborn rats. In addition, we considered it of interest to study whether $\mathrm{T}_{4}$ administered to the dam reaches the fetus during gestation and can correct the fetal hypothyroxinemia. 


\section{METHODS}

Animals and experimental design. Sprague-Dawley rats from the colony at the Developmental Psychobiology Laboratory in the Psychology Department at Bar-Ilan University were mated in polycarbonate cages $(38 \times 30 \times 27 \mathrm{~cm})$ with grid floors. Cages were checked daily, and the day in which a vaginal plug was secreted and detected was considered $\mathrm{d} 1$ of gestation (G-1). Parturition occurred between G-21 and G-23. Pregnant rats were housed individually in polycarbonate cages $(38 \times 30 \times 27 \mathrm{~cm})$ with stainless steel wire lids and wood shavings as bedding material. Food and tap water were continuously available in the cage top. Lights in the colony were on from 0500 to $1900 \mathrm{~h}$ and temperature was maintained between 21 and $25^{\circ} \mathrm{C}$. All conditions and treatments were in accordance with recommended humane conditions.

In experiment 1 , the pregnant dams were divided into three experimental groups: MMI [1-methylimidazole-2-thiol, which crosses the placenta and blocks both maternal and fetal thyroid function (15); Sigma Chemical Co.] treated $(n=9)$, MMI + $\mathrm{T}_{4}$ treated $(n=10)$, and controls $(n=11)$. Two of these groups were given $0.02 \% \mathrm{MMI}$ (as in Ref. 16) as drinking water from G-10 to parturition. The third group (controls) received unaltered drinking water throughout pregnancy. From G-16 to term all rats received daily i.p. injections. One of the MMI-treated groups received $18 \mu \mathrm{g} / \mathrm{kg}$ body weight levothyroxine sodium (Synthroid, Boots Pharmaceuticals, Inc., Lincolnshire, IL), whereas the other two groups (MMI and control) received $0.9 \%$ saline. Injection volume was $1 \mathrm{~mL} / \mathrm{kg}$ body weight. In experiment 2 , the dose of $\mathrm{T}_{4}$ was increased to ensure sufficient delivery by the oral route, and the MMI dose was increased in an effort to maximize its effect. Pregnant rats drank tap water until d G-9. From G-10 until parturition they received either 1 ) tap water, 2) MMI $(0.04 \%)$, or 3) MMI (0.04\%) and L- $\mathrm{T}_{4}(50$ $\mu \mathrm{g} / 100 \mathrm{~mL}$ solution, mean daily intake $=52.6 \pm 1.6 \mu \mathrm{g} / \mathrm{kg}$ body weight).

Tail blood spotted on filter paper was collected from the dams in experiment 1 on three occasions: before mating, on G-15, and within 1-16 $\mathrm{h}$ after parturition, and in experiment 2 on two occasions: before mating and after parturition. In both experiments within $1-16 \mathrm{~h}$ after parturition, trunk blood was collected after decapitation from two newborn pups (one male and one female) from each dam and spotted on filter paper (with special care not to include body fluids).

Measures and statistical analysis. After drying, all filter paper blood samples were kept in a cool, dark place. Samples from each experiment were assayed in duplicate, in a single assay in the National Screening Laboratory for Congenital Hypothyroidism, at the Sheba Medical Center. The Neonatal RIA kit for $\mathrm{T}_{4}$ (DPC, Los Angeles, CA) was used (14). The kit's buffer contains a high concentration of $\mathrm{T}_{4}$ displacing agents (from albumin and thyroid binding globulin, details not provided by the manufacturer). This, according to the manufacturer, together with the buffer's high ionic strength (which precludes red blood cells from interfering with the assay), allows measurement of $\mathrm{T}_{4}$ in a variety of animal species with this kit. The assay's sensitivity is $0.05 \mu \mathrm{g} / \mathrm{dL}$.
The assay's reliability for rat data were examined in a number of ways. First, intraassay reliability was studied by comparing the $\mathrm{T}_{4}$ levels assessed from duplicates from the same blood spots examined in a single assay. The mean intraassay CV of the RIA was between 8 and $12 \%$ on separate runs. The results for experiment 1 showed $r=0.88, p<0.01$ for a sample of 17 postpartum rats and $r=0.73, p<0.01$ for a sample of 38 newborn rat pups, and in experiment 2 the correlation between the duplicates from 20 dams (almost all assessed twice at different times, $n=39$ pairs of duplicates) was $r=0.94(p<0.01)$, and from 42 newborn pups $r=0.89$ $(p<0.01)$. Second, interassay (or test-retest) reliability was assessed by reexamining the blood spots from 12 rats (four postpartum and eight newborn pups) $1 \mathrm{wk}$ later. The results showed a $r=0.90\left(p<0.01 ;\right.$ mean $\mathrm{T}_{4}$ level $=1.11 \mu \mathrm{g} / \mathrm{dL}$, mean $\mathrm{CV}=14.44 \%$; this $\mathrm{CV}$ is similar to those reported for interasssay reliability of rat serum $\mathrm{T}_{4}$ [mean $\mathrm{CV}=$ between 9.6 and 20.7\%) assessed by the Coat-A-Count Total $\mathrm{T}_{4}$ kit (DPC)]. And third, $\mathrm{T}_{4}$ levels assessed from serum and from filter paper were highly correlated $(r=0.88, p<0.001$; based on pups from 19 litters). The $\mathrm{T}_{4}$ levels ranged from 0.53 to $3.16 \mu \mathrm{g} / \mathrm{dL}$, which is around the absolute range of the (euthyreotic) female Sprague-Dawley rat $\mathrm{T}_{4}(0.8-4.8 \mu \mathrm{g} / \mathrm{dL})$ assessed by the CoatA-Count Total $\mathrm{T}_{4}$ kit (DPC).

Maternal body weight during gestation and the newborn pups' weight, length, number, and sex ratio were recorded. All the results were analyzed by analysis of variance with post hoc contrasts and Duncan's multiple range tests when required (17).

\section{RESULTS}

\section{Maternal $\mathbf{T}_{4}$ Levels}

Experiment 1. The blood $\mathrm{T}_{4}$ level in the three groups did not differ before mating, but on G-16, both MMI-treated groups showed significantly lower levels than controls $(F(2,26)=$ 14.83, $p<0.001)$. After parturition, $\mathrm{T}_{4}$ levels in the three groups differed significantly from each other $(F(2,26)=$ $26.60, p<0.001) . \mathrm{T}_{4}$ treatment significantly attenuated maternal $\mathrm{T}_{4}$, resulting in levels higher than in the MMI group but lower than in controls (Table 1).

Experiment 2. Tail blood $\mathrm{T}_{4}$ concentrations were not significantly different in the three groups before mating (Table 1 ). However, after parturition, MMI-alone-treated rats had significantly lower $\mathrm{T}_{4}$ levels than water-drinking and $\mathrm{MMI}+\mathrm{T}_{4^{-}}$ drinking rats $(F(2,17)=8.30, p<0.01)$. Paired $t$ tests further showed that although the MMI-treated group showed a significant reduction in blood $\mathrm{T}_{4}$ levels from the first to the second measurement $(t(8)=8.22, p<0.01)$, the slight reductions evident in the control and MMI $+\mathrm{T}_{4}$ groups were not significant $(p>0.25)$. Thus, $\mathrm{L}_{-} \mathrm{T}_{4}$ in the drinking water corrected the rat dams' MMI-induced hypothyroxinemia.

\section{Neonatal $\mathrm{T}_{4}$ Levels}

Experiment 1. The blood $\mathrm{T}_{4}$ levels of newborn pups differed significantly between the two prenatal treatment groups ( $F$ $(2,54)=11.61, p<0.001)$. Prenatal $\mathrm{T}_{4}$ treatment resulted in 
Table 1. $T_{4}$ levels [mean (SEM) $\mu \mathrm{g} / \mathrm{dL}$ ] of rat dams, before mating, on gestation d 16 and after parturition, and of the newborn pups

\begin{tabular}{|c|c|c|c|c|c|c|}
\hline \multirow[b]{2}{*}{ Group } & \multirow{2}{*}{$\bar{n}$} & & \multicolumn{2}{|c|}{$\mathrm{T}_{4}$ levels } & \multicolumn{2}{|c|}{ Pups } \\
\hline & & Before & d 16 & Birth & $n$ & d 1 \\
\hline \multicolumn{7}{|l|}{ Experiment 1} \\
\hline Watcr & 10 & $2.35(0.14)$ & $2.05(0.21)$ & $2.79(0.25)$ & 19 & $1.08(0.07)$ \\
\hline MMI & 9 & $2.23(0.19)$ & $0.74(0.11)^{*}$ & $0.53(0.17)^{*}+$ & 18 & $0.54(0.08)^{*}$ \\
\hline $\mathrm{MMI}+\mathrm{T}_{4}$ & 10 & $2.64(0.30)$ & $0.77(0.23)^{*}$ & $1.47(0.21)^{*} \div$ & 19 & $0.89(0.08)$ \\
\hline $\mathrm{MMI}$ & 8 & $3.35(0.23)$ & & $0.90(0.19)^{6} \dagger$ & 19 & $0.89(0.06) \div$ \\
\hline $\mathrm{MMI}+\mathrm{T}_{4}$ & 6 & $3.02(0.40)$ & & $2.41(0.41) \div$ & 9 & $1.24(0.11)$ \\
\hline
\end{tabular}

Treatments: water, tap water (controls); MMI, methimazole (0.02\% in experiment 1;0.04\% in experiment 2) in drinking water from gestation d 10. MMI + $\mathrm{T}_{4}$, MMI (as in previous group) with: $I$ ) daily i.p. injections of $\mathrm{t},-\mathrm{T}_{4}(18 \mu \mathrm{g} / \mathrm{kg})$ from gestation $\mathrm{d} 16$ to parturition $($ experiment 1$)$ or 2$) \mathrm{L}-\mathrm{T}_{4}(52 \mu \mathrm{g} / \mathrm{kg})$ in the drinking water from gestation d 10 to parturition (cxperiment 2 ).

"Significantly lower than controls (water).

$\dagger$ Significantly lower than the MMI $+\mathrm{T}_{4}$ group.

* Significantly higher than the MMI-alone group.

corrected neonatal $\mathrm{T}_{4}$ levels: although the MMI group had significantly lower levels than controls, the $\mathrm{MMI}+\mathrm{T}_{4}$-treated group had levels that did not differ from controls (Table 1).

Experiment 2. Trunk blood $\mathrm{T}_{4}$ levels in the pups born to dams that received $\mathrm{MMI}+\mathrm{T}_{4}$ or water alone (controls) were not significantly different; $\mathrm{T}_{4}$ levels of both these groups were significantly higher than in the MMI-alone group $(F(2,38)=$ 5.41, $p<0.01$; Table 1$)$. Thus, orally ingested $\mathrm{L}_{\mathrm{L}} \mathrm{T}_{4}$ in the MMI-treated pregnant rat reaches the fetus and significantly increases the newborn's blood $\mathrm{T}_{4}$ levels, correcting the nconate's hypothyroxinemia.

\section{Maternal Weight and Fertility}

Experiment 1. At the start of the experiment (G-10), there was no significant difference between the body weights of the pregnant dams in the three groups (Table 2). After $6 \mathrm{~d}$ of drinking MMI, the mean increase in body weight was lesser for the MMI-treated rats than for controls, but the difference was not statistically significant $(p<0.1)$. After parturition, the MMI-only treated group weighed significantly less than the controls, although the weight of the $\mathrm{MMI}+\mathrm{T}_{4}$ postpartum dams did not differ from that in the other two groups $(F(2,28)$ $=3.99, p<0.05$ ).

The mean number of pups delivered per litter (live and dead births), their sex ratio, and mean body or tail length were not significantly different in the three groups (Table 2). The mean body weight of the pups born in the control group was significantly greater than the weight of the pups treated with MMI. In contrast, the weight of the newborns in the MMI $+\mathrm{T}_{4}$ group was not significantly reduced compared with the controls ( $F$ $(2,28)=3.448, p<0.05)$. The pups of the three groups differed in their weight/length ratio $(F(2,28)=4.58, p<$ $0.05)$ : the two MMI-treated groups were less obese than the control group.

Experiment 2. The body weight of pregnant dams did not differ significantly between the three groups on any of the days of pregnancy (Table 2). However, the groups showed a significantly different pattern of weight gain over this period. Spe- cifically, between $\mathrm{d}$ G-10 and G-16, the two MMI-treated groups gained significantly less than did the controls $(F(2,16)$ $=5.15, p<0.05$ ).

The three treatment groups did not differ significantly in mean number of pups born (live or dead), the pups' sex ratio, body weight, length, tail length, and weight/length obesity ratio.

\section{DISCUSSION}

In this study we measured $T_{4}$ from rat blood spotted on filter paper, using the human neonatal RIA kit. Compared with untreated pregnant rats, subjects that received MMI in their drinking water exhibited significantly reduced blood $\mathrm{T}_{4}$ levels. The $\mathrm{T}_{4}$ values of both groups werc comparable to the values reported for female rats of the same strain by the manufacturer of the RIA kit. We also found high intraassay (duplicates), intcrassay, and intermethod (plasma-filter paper) correlations.

Daily i.p. administration of $1-\mathrm{T}_{4}$ from $\mathrm{G}-16$ until parturition significantly increased filter paper $\mathrm{T}_{4}$ levels in MMI-drinking rats. This shows that the exogenous $\mathrm{T}_{4}$ reached the maternal circulation. This increase was also observed in rats that received $\mathrm{T}_{4}$ orally in the drinking water from $\mathrm{G}-10$ until parturition.

The main goal of this study was to design a minimally invasive model for examining whether $\mathrm{T}_{4}$ administered to the dam during gestation would reach the fetus and be detcctable, in the newborns' circulation, by the simplest method. The results show that MMI-induced intrauterine hypothyroidism, at least as evidenced by low $\mathrm{T}_{4}$ levels in the newborns' blood (hypothyroxinemia), can be corrected by prenatal treatment of the mother with $\mathrm{T}_{4}$. A similar pattern of results was obtained by i.p. and oral routes of administration. These findings extend the report by Calvo et al. (5) that s.c. infusion of increasing doses of $\mathrm{T}_{4}$ into MMI-treated pregnant rats preferentially protected the brain of the hypothyroid fetus from $T_{3}$ deficiency, whereas fetal plasma $\mathrm{T}_{4}$ levels increased to a lesser degree. Taken together, these findings suggest the possibility that augmentation of the pregnant mother's circulating $\mathrm{T}_{4}$ levels 
Table 2. Maternal weight and fertility data

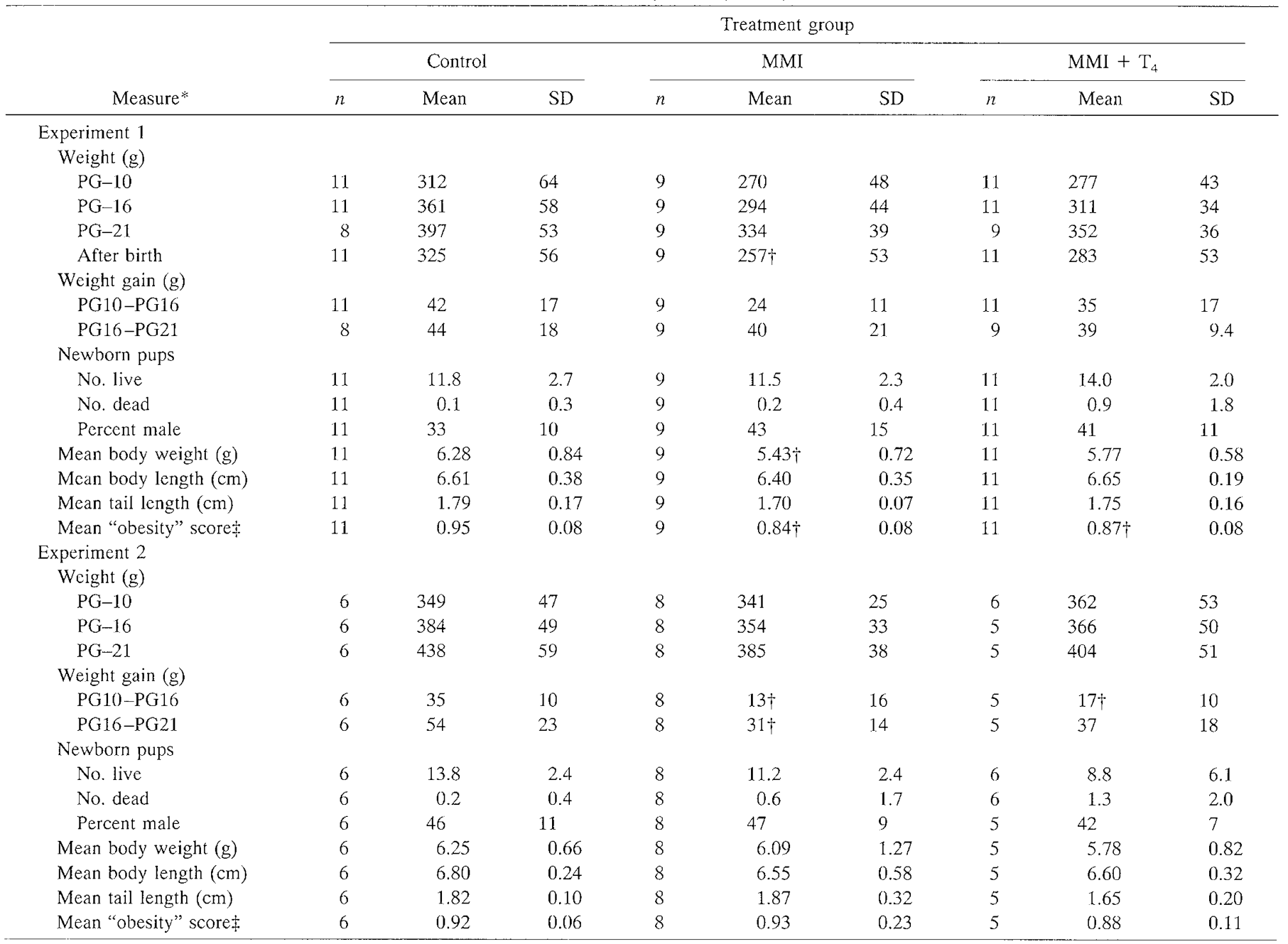

* PG, day post gestation.

$\uparrow$ Significantly lower than controls.

$\ddagger$ Mean body weight/mean body length.

may also serve to prevent the detrimental developmental (physiologic, behavioral, and cognitive) outcomes of in utero hypothyroidism. Further work with animal models with goitrogens, such as MMI and propylthiouracil, is needed first. The current method provides a minimally invasive way to examine this issue.

A number of important limitations exist in the current study. First, one should be aware that the finding of significant maternal-fetal $\mathrm{T}_{4}$ transfer was obtained in MMI-drinking pregnant rats. Although we do not have evidence, it is still possible that MMI alters the permeability of the placenta to $\mathrm{T}_{4}$ and that the results would be different in rats treated with other goitrogens or, more importantly, in naturally hypothyreotic rats. This qualification holds equally for reports from other laboratories, on maternal-fetal $\mathrm{T}_{4}$ transfer in MMI-drinking pregnant rats (e.g. see Refs. 5-7 and 16). Second, the doses of $\mathrm{T}_{4}$ used in this study were not very low, and the efficacy of lower doses, in the $1 \mu \mathrm{g} / \mathrm{kg}$ range, should be examined in future studies. We note, however, that the current doses were identical to some cases and very close to others, in which $\mathrm{T}_{4}$ replacement therapy was given prenatally (18) or postnatally (19). Furthermore, as mentioned above, Calvo et al. (5) reported that the fetal brain apparently preferentially absorbs the $T_{4}$ transferred from the mother. It is therefore likely that higher doses are needed to correct the peripheral deficiency in $T_{4}$. It is relevant also that the doses of $\mathrm{T}_{4}$ administered in the current study did not prevent body weight increase during the pregnancy of the MMI-treated dams, did not decrease litter size, and did not produce excessive blood $\mathrm{T}_{4}$ levels in the dams. It is possible, even so, that lower doses of $\mathrm{L}-\mathrm{T}_{4}$ would have yielded similar results. Third, a portion of the effects of MMI in the current study may be attributed to prenatal "starvation" or undernutrition. After parturition, both the dams and the pups treated prenatally with MMI (and not "corrected" with $\mathrm{T}_{4}$ ) weighed significantly less than controls. A prenatally "pair-fed" control group would have helped clarify the extent of the impact of this factor on the current results. And fourth, the validity of the rat (MMI) model for studying treatment of in utero hypothyroidism in humans should not be taken for granted.

The animal model provides a number of advantages that allow for further progress of research in this field. To our knowledge, this is the first study to examine maternal-fetal $\mathrm{T}_{4}$ 
transfer in rats whose pregnancies are carried to term, and the impact of the transfer in the newborn pups assessed. In other studies on this issue pregnancy was terminated at various times during gestation. Furthermore, use of the blood spotted on filter paper technique in rats for this type of study (as first reported here) opens up the opportunity to conduct long-term, postnatal psychomotoric follow-up studies of offspring from treated (hypothyreotic and $\mathrm{T}_{4}$-treated) pregnancies. This results from the ability to reliably assess blood $\mathrm{T}_{4}$ levels from one drop of blood, thus allowing repeated examination of the mother and making it necessary to kill only one pup at a given time. This can allow the rest of the litter to develop, enabling the assessment of the behavioral and physiologic consequences of prenatal insult and therapy. Furthermore, this type of study need not be restricted to $\mathrm{T}_{4}$ : as in humans, blood spots on filter paper can be used in rats to assay levels of other hormones, e.g. TSH, 17-OH-progesterone, and cortisol $(14,20,21)$.

In conclusion, we report a convenient and minimally invasive rat model that will enable future postnatal studies examining whether maternal-fetal $\mathrm{T}_{4}$ transfer can correct the detrimental effects of in utero hypothyroidism.

Acknowledgments. The authors thank Avraham Goldstein for assistance in experiment 1, Ofra Schwartz for help in performing experiment 2, and Ora Amado and Yehudit Brook for performing the RIA.

\section{REFERENCES}

1. Fisher DA 1986 The unique endocrine milieu of the fetus. J Clin Invest 78:603-61

2. Fisher DA, Klein AK 1981 Thyroid development and disorders of thyroid function in newborn. $N$ Engl J Med 304:702-712

3. Roti E, Fang SL, Green K, Emerson CH, Braverman LE 1981 Human placenta is an active site of thyroxine and $3,3^{\prime}, 5$ triiodothyronine tyrosyl ring deiodination. J Clin Endocrinol Metab 53:498-501

4. Roti E, Gnudi A, Braverman LE 1983 The placental transport, synthesis and metabolism of hormones and drugs which affect thyroid function. Endocrinol Rev $4: 131-149$
5. Calvo R, Obregon MJ, Ruiz de Ona C, Escobar del Rey F, Morreale de Escobar G 1990 Congenital hypothyroidism as studied in rats. Crucial rolc of maternal thyroxine but not of $3,5,3^{\prime}$-triiodothyronine in the protection of the fetal brain. J Clin Invest $86: 889-899$

6. Morreale de Escobar G, Pastor R, Obregon MJ, Escobar del Rey F 1985 Effects of maternal hypothyroidism on the weight and thyroid hormone content of rat embryonic issues, before and after onset of fetal thyroid function. Concentrations in the rat Endocrinology 117:1890-1900

7. Obregon MJ, Mallol J, Pastor R, Morreale de Escobar G, Escobar del Rey F 1984 L-Thyroxine and 3,5,3'-triio-L-thyronine in rat embryos before onset of fetal thyroid function. Endocrinology 114:305-307

8. Vulsma T, Gons MH, De Viljlder JJM 1989 Maternal-fetal transfer of thyroxine in congenital hypothyroidism duc to total organification defect or thyroid agenesis. $N$ Engl J Med 321:13-16

9. Sack J, Kaiserman I, Siebner R 1993 Maternal-fetal T4 transfer docs not suffice to prevent the effects of in utero hypothyroidism. Horm Res 39:1-17

10. Dussault JH 1989 Action of thyroid hormones on brain development. In: Delange F, Fisher DA, Glinoer D (eds) Research in Congenital Hypothyroidism. NATO ASI Scrics, Plenum Press, New York, pp 95-102

11. Gloriex J, Dussault J, Van Vilet G 1992 Intellectual development at age 12 ycars of children with congenital hypothyroidism diagnosed by neonatal screening. $\mathbf{J}$ Pediatr 121:581-584

12. Wolter R, Noel P, DeCock P, Craen M, Eernould CH, Malvaux P, Verstraeten F, Simons J, Mertens S, Van Broek N, Vanderschueren-Lodewyckk M 1980 Neuropsychological study in treated thyroid dysgenesis. Acta Paediatr Scand 277:4l-46

13. Rovet JF, Ehrlich RM, Sorbara D 1987 Intellectual outcome in children with fetal hypothyroidism. J Pediatr 110:70()-704

14. Eldar D, Gelemter I, Sack J 1991 Blood-spotted filter paper measurements of thyroxine and thyroid-stimulating hormone in the follow-up of children with congenital hypothyroidism. Horm Res 34:219-223

15. Marchant B, Brownlic BEW, McKay Hart D, Horton PW, Alexander WD 1977 Tho placental transfer of propylthiouracil, methimazole and carbimazolc. J Clin Endocrinol Metab 45:1187-1193

16. Calvo R, Obregon MJ, Escobar del Rey F, Morreale de Escobar G 1992 The rat placenta and the transfer of thyroid hormones from the mother to the fetus. Effects of matcrnal thyroid status. Endocrinology 131:357-365

17. Winer BJ 1971 Statistical Principles in Experimental Designs. McGraw-Hill, New York

18. Bonet B, Herrera E 1988 Different response to maternal hypothyroidism during the first and second half of gestation in the rat. Endocrinology 122:450-455

19. Nathaniel EJH, Nathanicl DR, Nathaniel LM, Burt S, Panfili F 1988 Effect of thyroxine replacement therapy on the growth patterns of body, brain, and cerebellum in the neonatal hypothyroid rat. Exp Neurol 101:1-16

20. Berry J, Betts P, Wood PJ 1986 The interpretation of bloodspot 17 alphahydroxyprogesterone levels in tcrm and pre-term neonates. Ann Clin Biochem 23:546-551

21. Kraiem Z, Sack J, Brish M 1985 Serum cortisol levels: The first 10 days in full-term and preterm infants. Isr $J$ Med Sci 21:170-172 